\title{
Development of graphene-nanometre-sized cerium oxide-incorporated aluminium and its electrochemical evaluation
}

\author{
P. Muhamed Ashraf ${ }^{1} \cdot$ Saly N. Thomas ${ }^{1} \cdot$ Leela Edwin $^{1}$
}

Received: 16 April 2014/Accepted: 17 March 2015/Published online: 26 March 2015

(c) The Author(s) 2015. This article is published with open access at Springerlink.com

\begin{abstract}
Graphene-nanometre-sized cerium oxide-incorporated aluminium was prepared and its electrochemical and surface morphological characteristics were studied. The atomic force micrographs and scanning electron micrographs evaluation highlighted that the graphene and nanometre-sized cerium oxide in aluminium had decreased the surface roughness and improved the surface morphological characteristics. The graphene: nanometresized cerium oxide (ratios 1:2 or 2:1) with lesser amounts of particle in the matrix showed excellent corrosion resistance in the marine environment as evidenced by linear polarization, electrochemical impedance and weight loss studies. Introduction of graphene in the aluminium matrix showed a barrier separation between the outermost layer and inner layer, increased roughness and increased corrosion. The material is found to be a potential candidate for use in marine environment.
\end{abstract}

Keywords Graphene - Metal matrix composite · Corrosion

P. Muhamed Ashraf

ashrafp2008@gmail.com

Saly N. Thomas

salynthomas@gmail.com

Leela Edwin

leelaedwin@gmail.com

1 Fishing Technology Division, ICAR - Central Institute of Fisheries Technology, Matsyapuri PO, Cochin, Kerala 682029, India

\section{Introduction}

Free-standing stable two-dimensional graphene synthesis has instigated lots of research on its novel electrical properties (Berger et al. 2004; Geim and Novoselov 2007; Novoselov et al. 2005; Zhang et al. 2005) and its sensitivity to changes in conductance during sensor applications (Schedin et al. 2007; Wehling et al. 2008). Graphene has exceptional mechanical, thermal and chemical stability and electrical conductivity (Mattevi et al. 2011; Wintterlin and Bocquet 2009). Graphene, coated or grown on surfaces will add only negligible thickness on the thermally and electrically conductive layer (Novoselov et al. 2004). Graphene has unique two-dimensional structures with bands showing linear dispersion around the Fermi level where they touch at a single point. Good conductivity and high stability in ambient conditions make graphene a potential candidate for nanoelectronics (Geim and Novoselov 2007). The findings described above highlight that interaction of metals with graphene has potential scope for various applications.

The metal substrate and graphene can form either a physisorption interface with charge transfer (Giovannetti et al. 2008; Pletikosić et al. 2009, Barraza-Lopez et al. 2010) or a chemisorption interface with orbital hybridization (Barraza-Lopez et al. 2010; Bertoni et al. 2005; Eom et al. 2009; Marchini et al. 2007; Sutter et al. 2008; Uchoa et al. 2008; Varykhalov et al. 2008). A physisorption interface does not form chemical bonding and preserves graphene's intrinsic $\pi$-band structure, but a chemisorption interface forms metal carbide bonding and disturbs graphene's electronic structure through a strong hybridization of metal's d-orbital and graphene's $\pi$-orbital. Furthermore, chemisorption interfaces, compared to physisorption interfaces, are more likely to form realistic electrode contacts 
because of their stronger bonding to graphene. It is worthwhile to note that recently Vanin et al. (2010) have applied van der Waals density functional theory to study metal-graphene interfaces and obtained the results of all weakly bonded interfaces which are different from previous density functional theory calculations.

Extensive research has been done in aluminium for developing composites by incorporating carbon nanotubes and other nanomaterials since the product will be lightweight aluminium composites. Literature revealed positive and negative reports regarding these types of composites (Kuzumaki et al. 1998) and the main differences were in the dispersion, method of fabrication, interfacial reaction, etc. Bartolucci et al. (2011) prepared graphene aluminium composites and studied the physical properties and predicted that the composite has lower strength and hardness. The authors have not studied the electrochemical aspects of the graphene aluminium. Incorporation of cerium oxide, cerium oxide and titanium oxide mixtures in aluminium have exhibited improved material performance (Ashraf and Shibli 2008; Ashraf and Edwin 2013). Addition of cerium oxide along with graphene may improve the material performance. In the present study attempts are made to incorporate graphene and nanometre-sized cerium oxide in pure aluminium to evaluate the material performance by electrochemical means.

\section{Materials and methods}

Electrolytic-grade pure aluminium (99.80\%) ingots were used for fabrication of metal matrix composites and the concentration of metallic impurities are described elsewhere (Ashraf and Edwin 2013). The cerium nitrate, cerium oxide (both from $\mathrm{CDH}$, Mumbai) ammonium hydroxide, chemically reduced graphene (Quantum Materials Corporation, India) and sodium chloride from Merck were used for the experiment. Nanometre-sized cerium oxide was prepared by precipitation (Fu et al. 2005) using cerium nitrate and ammonium hydroxide. Ammonium hydroxide solution was added to cerium nitrate solution at $80{ }^{\circ} \mathrm{C}(\mathrm{pH} 8.00)$ with constant stirring by a magnetic stirrer. The mixture was kept at that temperature for $2 \mathrm{~h}$. The precipitate was collected by filtration and calcined at $350{ }^{\circ} \mathrm{C}$ in a muffle furnace in presence of air.

The ingots of pure aluminium were melted at $800 \pm 10{ }^{\circ} \mathrm{C}$ in a muffle furnace. The required amount of nano-sized cerium oxide and graphene were added to the pure aluminium melt and stirred using an SiC rod. The melt was again kept in the muffle furnace for another $15 \mathrm{~min}$ at the same temperature and poured into a red brick mould. Further processing of the composite was done as described
Table 1 Details of nanometre-sized cerium oxide and graphene concentration in different treatments

\begin{tabular}{lll}
\hline Treatment & \% Nanocerium oxide & $\%$ Graphene \\
\hline A1 & 0 & 0 \\
A2 & 0 & 0.05 \\
A3 & 0.01 & 0.01 \\
A4 & 0.02 & 0.02 \\
A5 & 0.05 & 0.05 \\
A6 & 0.10 & 0.10 \\
A7 & 0.01 & 0.02 \\
A8 & 0.02 & 0.04 \\
A9 & 0.02 & 0.01 \\
A10 & 0.04 & 0.02 \\
A11 & 0.06 & 0.03 \\
\hline
\end{tabular}

in our previous papers (Ashraf and Edwin 2013). Eleven batches of aluminium composites were prepared by incorporating graphene and nanometre-sized cerium oxide in different concentrations as described in Table 1.

Electrochemical measurements, electrochemical impedance spectroscopy (EIS) and linear sweep voltammetry analyses were carried out using an Autolab PGSTAT 30 plus FRA2 electrochemical analyzer. EIS measurements, EIS data fitting, potentiodynamic measurements and weight loss experiments were carried out as described elsewhere (Ashraf and Edwin 2013). All analyses were carried out with at least three replicates. The open circuit potential variation of the coupons was measured by exposing in $3.5 \% \mathrm{NaCl}$ for 40 days. The potential was recorded every day with reference to $\mathrm{Ag} / \mathrm{AgCl}(3 \mathrm{M} \mathrm{KCl})$ reference electrode at room temperature.

The surface of fresh micro and nanocerium oxide-incorporated aluminium coupons were ground using a series of $\mathrm{SiC}$ papers up to 2000 grit followed by etching with $1 \%$ (w/v) $\mathrm{NaOH}$ solution and their surface morphology was studied using Hitachi scanning electron microscope (SEM) at $15 \mathrm{keV}$. The surface topography of the coupons was measured using non-contact mode of Park Systems XE100 Atomic force microscope (AFM). General statistical analysis was carried out using Microsoft Excel software.

\section{Results and discussion}

\section{Graphene and nanocerium oxide}

Surface morphological characteristics of the prepared nano-sized cerium oxide were described in the previous papers (Ashraf and Edwin 2013). The graphene particles used in the present study was chemically reduced graphene and the same was described in the manuscript throughout 


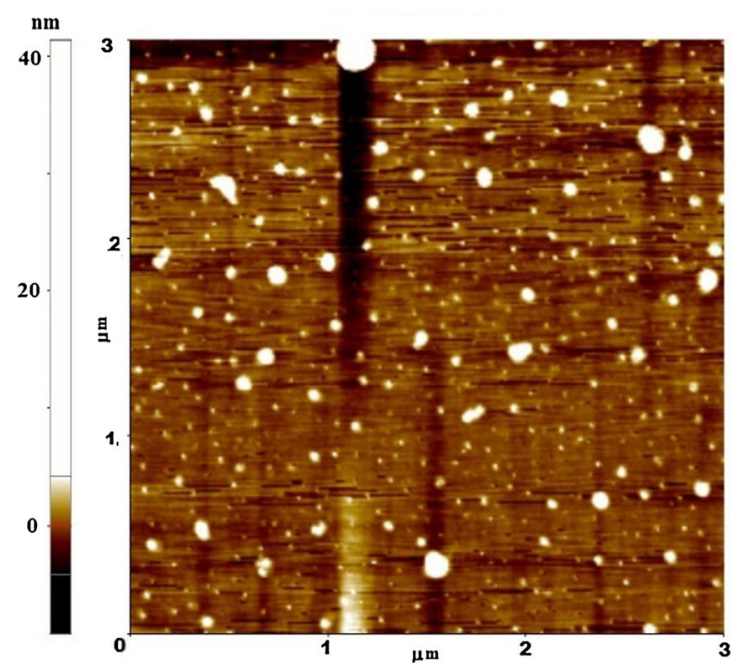

A

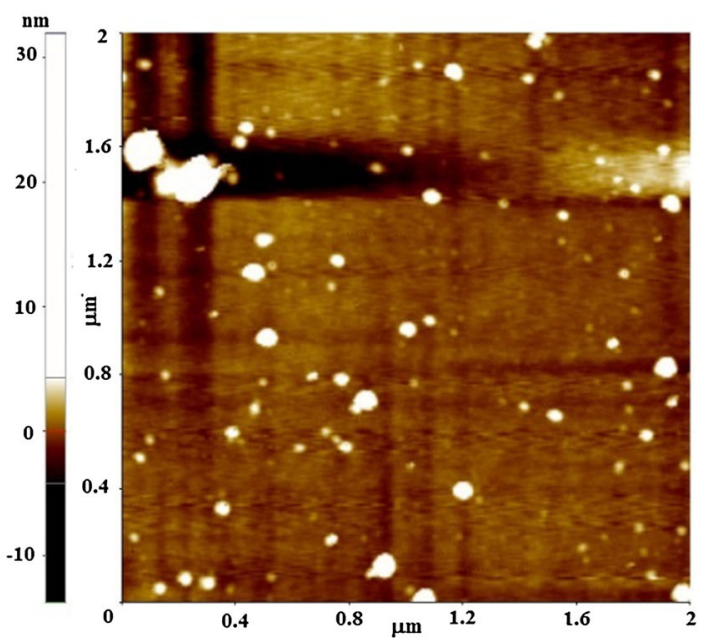

B

Fig. 1 AFM images of graphene (a) and nanocerium oxide (b)

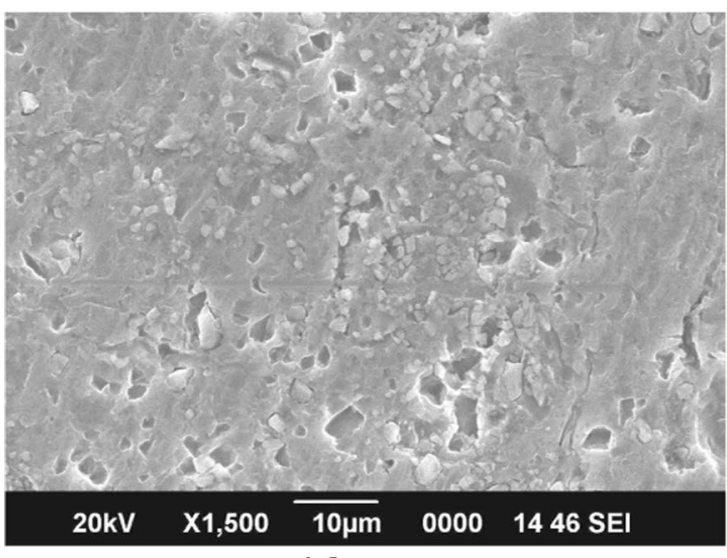

A2

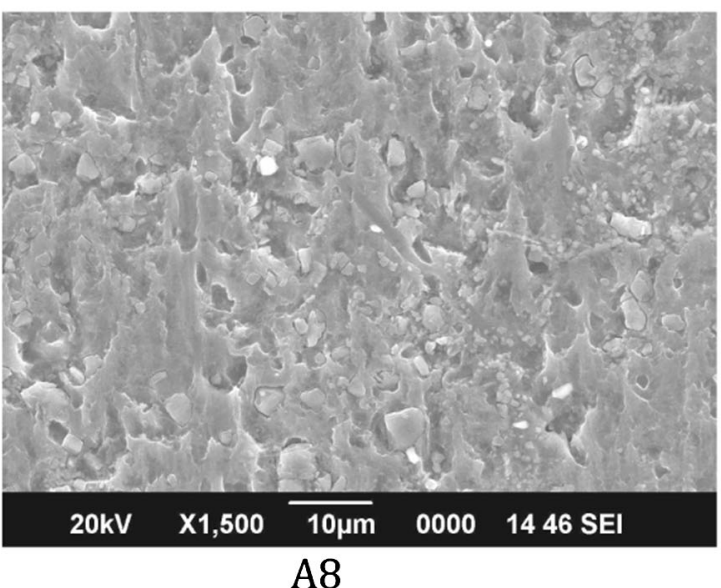

Fig. 2 SEM images of graphene and nanometre-sized cerium oxide mixtures-incorporated aluminium, where $\mathbf{A 2}$ is graphene-incorporated aluminium, A6 nanometre-sized cerium oxide:graphene ( $0.1 \%$ each),
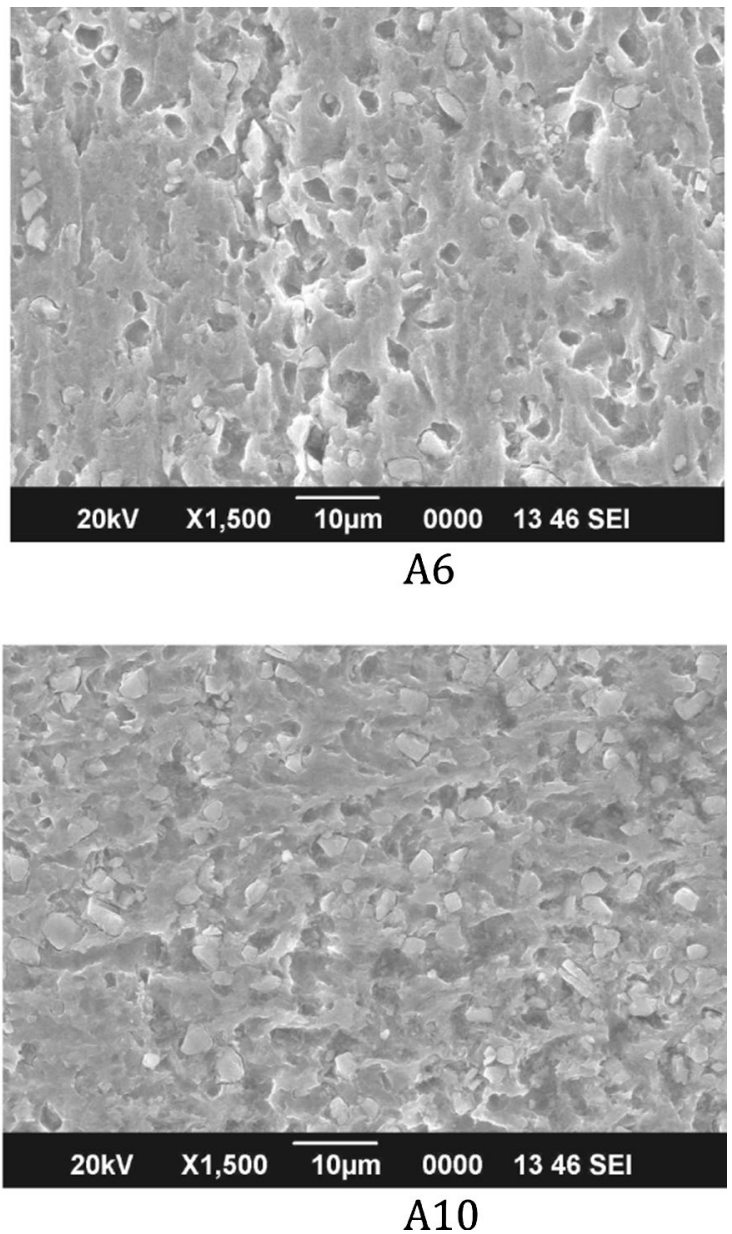

A8 is nano-sized cerium oxide:graphene (0.02:0.04 \%) aluminium and A10 nanometre-sized cerium oxide:graphene in 0.04:0.02\% 
Fig. 3 AFM images of pure aluminium (A1), graphenealone-incorporated aluminium (A2) and nanometre-sized cerium oxide:graphene mixure in different concentration incorporated aluminium (A3A11)

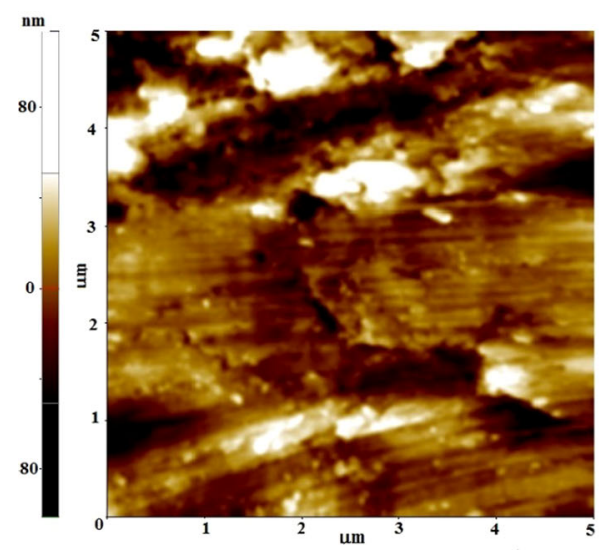

A1 pure aluminium

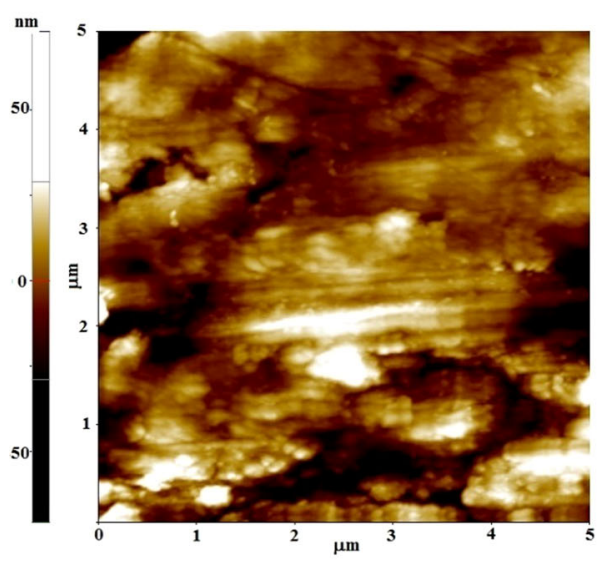

A3

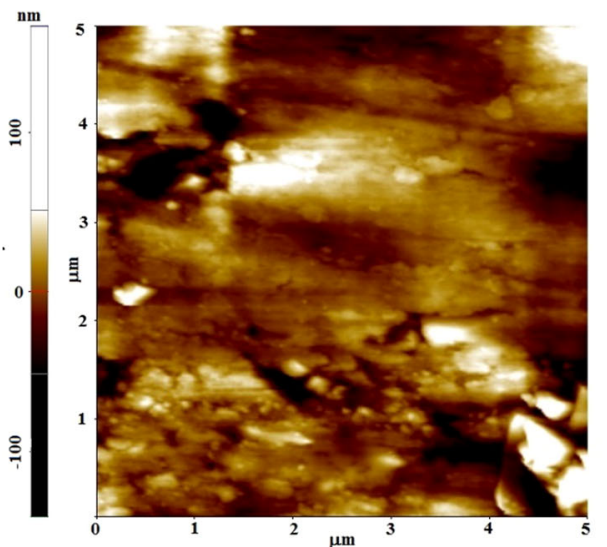

A5

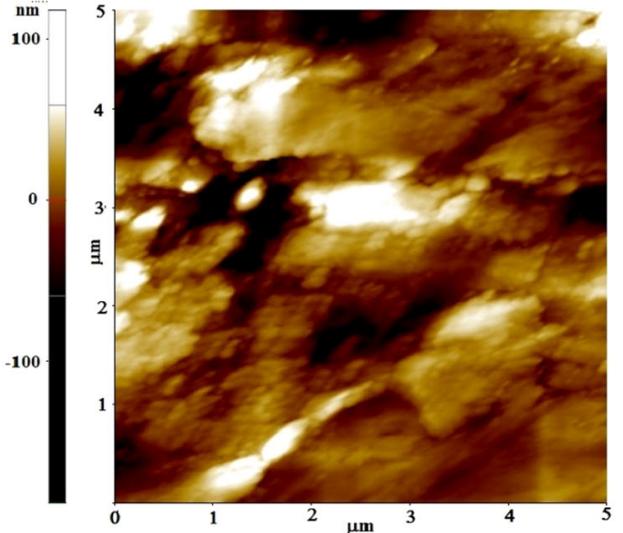

A2

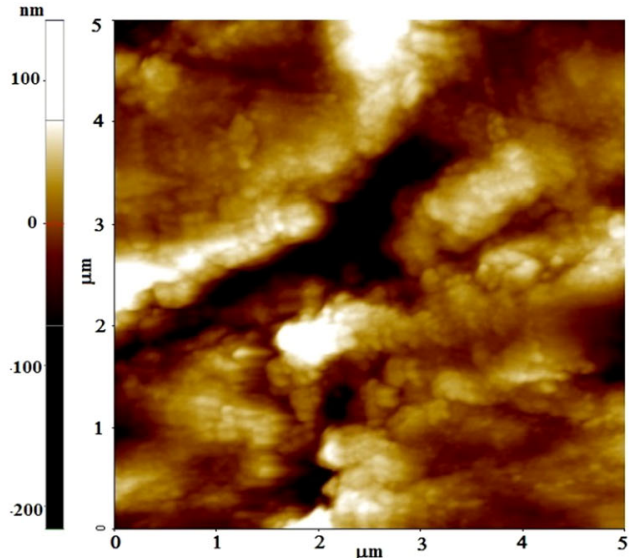

A4

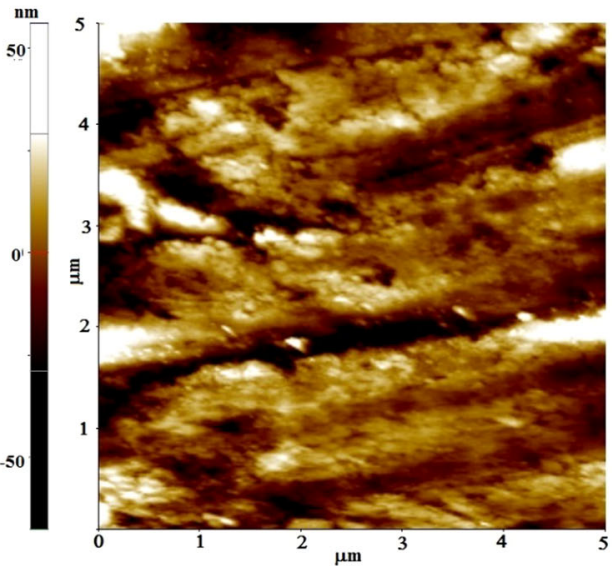

A6 as graphene. The materials were evaluated for the surface and size characteristics using AFM and are shown in Fig. 1. The graphene particle size ranged from 50 to $93 \mathrm{~nm}$ and the average diameter was $73 \mathrm{~nm}$. Similarly the nanosized cerium oxide ranged from 40 to $70 \mathrm{~nm}$ and the average size was about $47 \mathrm{~nm}$.

\section{Morphological characteristics}

SEM images of prepared graphene and nano-sized cerium oxide-incorporated aluminium are shown in Fig. 2. The wider grain size was exhibited by graphene-alone-incorporated aluminium. The aluminium with mixture of 


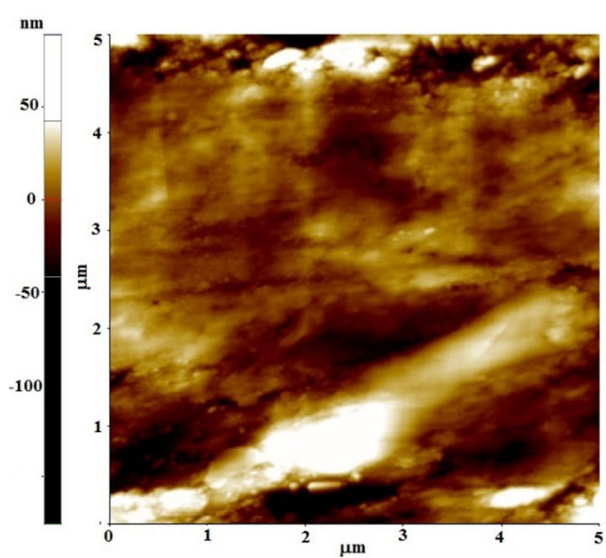

A7

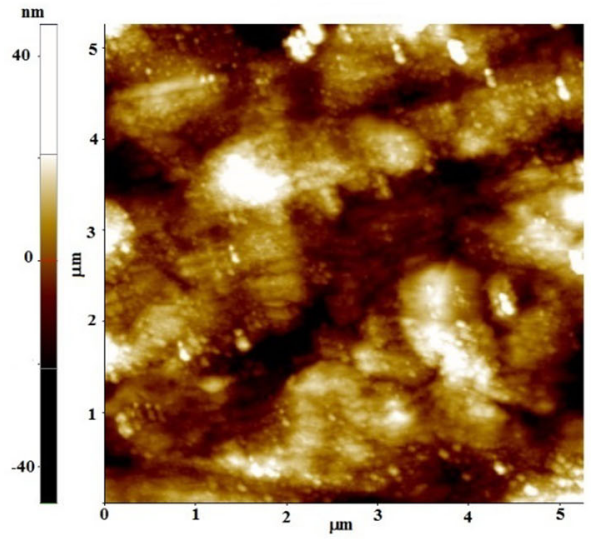

A9

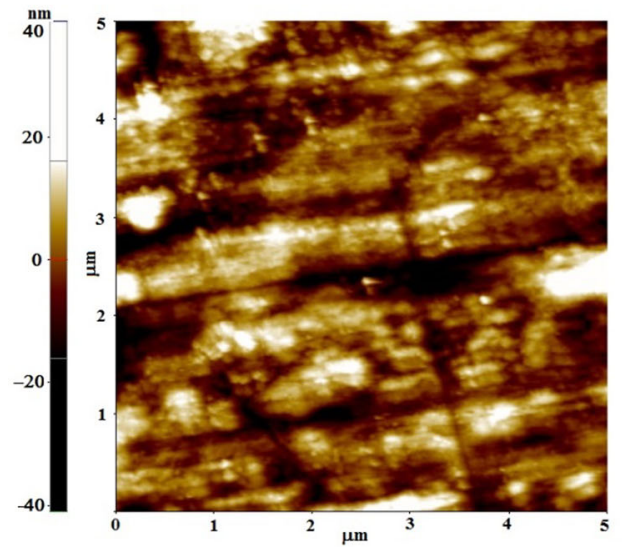

A11

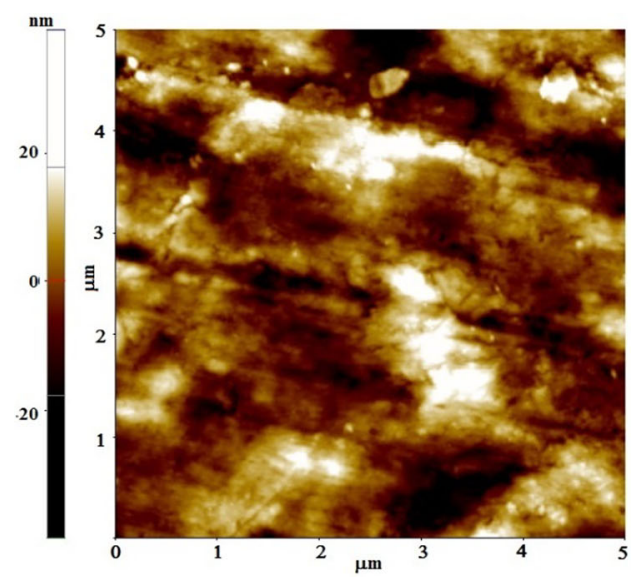

A8

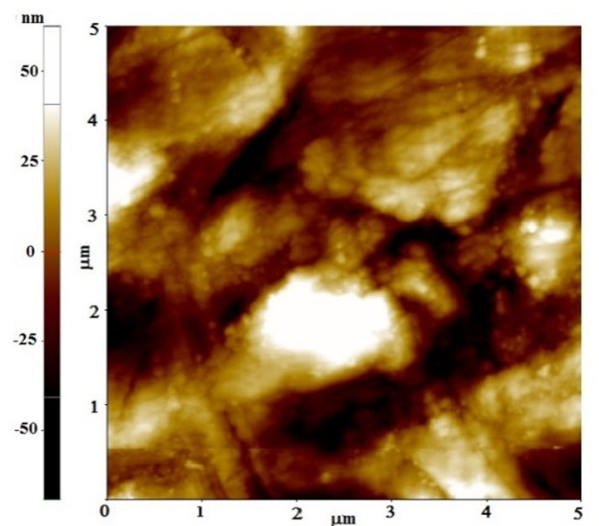

A10

Fig. 3 continued

nanometre-sized cerium oxide and graphene exhibited shorter grain sizes compared to graphene alone. Graphene:nanocerium oxide in 2:1 and 1:2 (A8 and A10) ratio exhibited more compact and shorter distance between the grain boundaries. Introduction of nanometre-sized cerium oxide along with graphene in aluminium in different ratios showed substantial improvement in morphological characteristics. Nanoparticle reinforcement will inhibit grain boundary pinning and will lead to finer grain morphologies (Deng et al. 2007). Studies of Bartolucci 
et al. (2011) showed similar results in the case of exclusively graphene-incorporated aluminium and it was explained the phenomenon was due to the formation of aluminium carbide in the grain boundaries.

AFM images of pure aluminium, graphene and graphene:nanometre-sized cerium oxide-incorporated aluminium are shown in Fig. 3. There was significant improvement in the topography of pure aluminium when graphene:nano-sized cerium oxide particles were

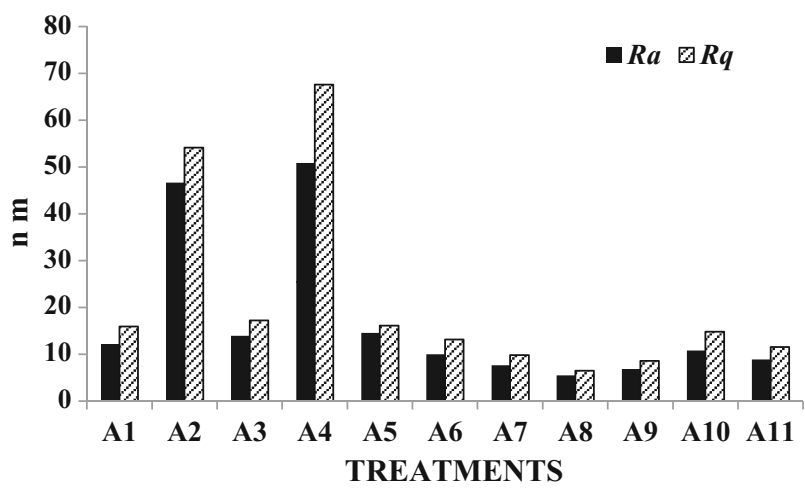

Fig. 4 AFM amplitude parameters, average roughness $(R a)$ and root mean square roughness $(R q)$ of pure aluminium, graphene-incorporated aluminium and mixtures of nano-sized cerium oxide and graphene-incorporated aluminium incorporated into the matrix. Incorporation of graphene alone in the aluminium increased the surface grains compared to nanometre-sized cerium oxide and mixtures of graphene and nanometre-sized cerium oxide. To characterize the surface topography of AFM images, the amplitude parameters were analysed and shown in Fig. 4. The average roughness $(\mathrm{Ra})$ and root mean square roughness $(R q)$ were generally used as amplitude parameters. The latter will provide information on the temporal changes in the creation of new surfaces as well as spatial differences (Raposo et al. 2007). The roughness coefficient increased significantly when graphene was incorporated into the aluminium and also in the case of graphene:nano-sized cerium oxide $0.02 \%$ each. There was significant $(p=0.009)$ reduction in the roughness coefficients in the case of A7-A9 where the ratios of graphene and nanometre-sized cerium oxide was either $1: 2$ or $2: 1$. The results showed that these two components act synergistically to improve the surface characteristics.

\section{Polarisation studies}

The coupons were subjected to the linear sweep voltammetry and the results are shown in Fig. 5 and Table 2. The substantially lower corrosion potential $\left(E_{\text {corr }}\right)$ was exhibited by all the aluminium incorporated with nanometre-sized
Fig. 5 Tafel slopes of graphene-incorporated aluminium (A2) and nanometresized cerium oxide and graphene mixtures in different concentrations incorporated aluminium $A 3-A 11$. The measurement was done $\mathrm{Ag} /$ $\mathrm{AgCl}(3 \mathrm{M} \mathrm{KCl})$ as reference, $\mathrm{Pt}$ as counter and sample working electrode in $3.5 \% \mathrm{NaCl}$ at $25 \pm 2{ }^{\circ} \mathrm{C}$
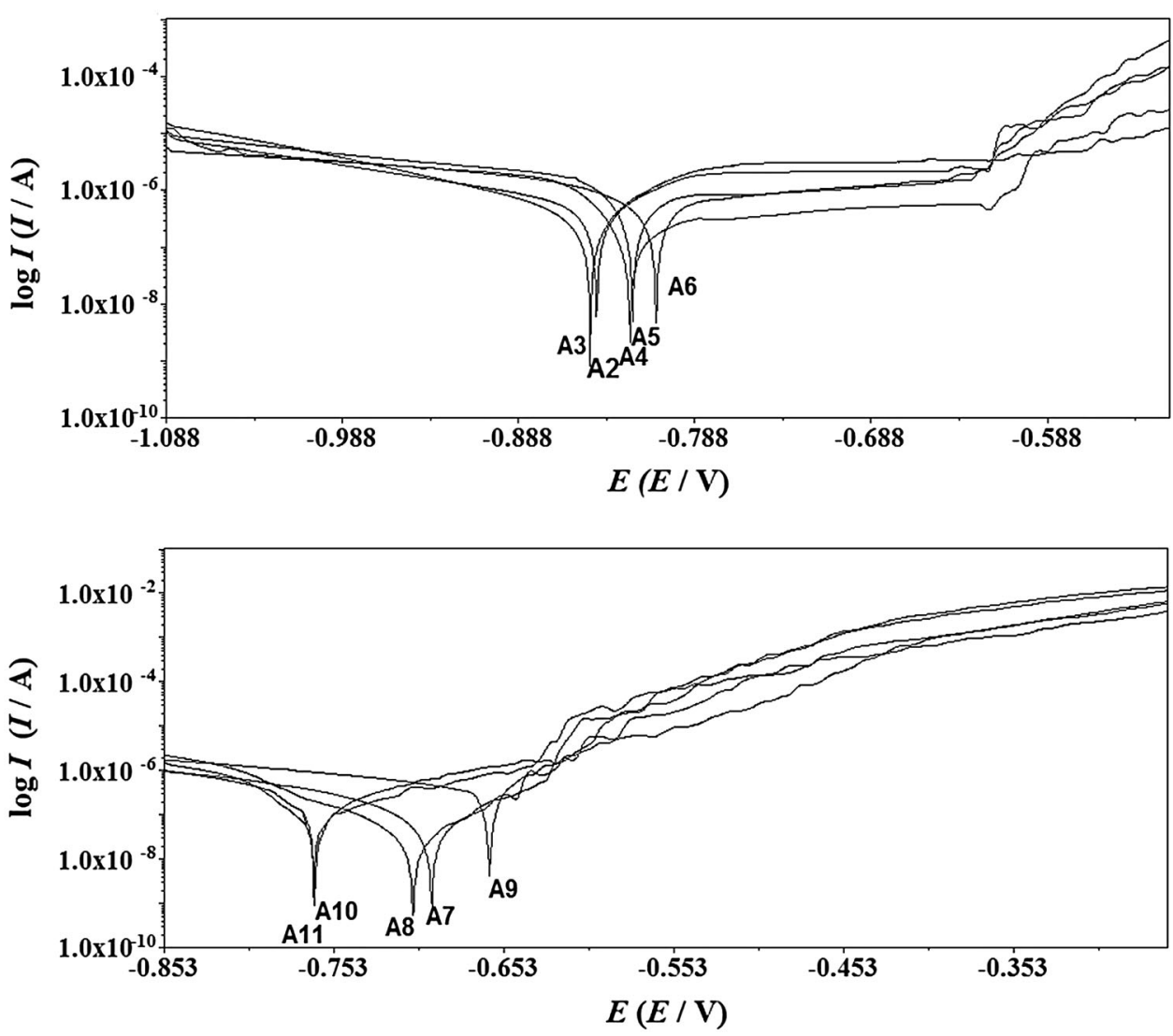
Table 2 Linear sweep voltammetric data of pure aluminium, graphene-incorporated aluminium and mixtures of graphene and nanosized cerium oxide-incorporated aluminium

\begin{tabular}{llll}
\hline Treatments & $\begin{array}{l}\text { Corrosion } \\
\text { potential } E_{\text {corr }} \\
\mathrm{V}\end{array}$ & $\begin{array}{l}\text { Corrosion current } \\
\text { density } I_{\text {corr }} \mathrm{A} \mathrm{cm}^{-2}\end{array}$ & $\begin{array}{l}\text { Polarisation } \\
\text { resistance } R_{\mathrm{p}} \\
\Omega \mathrm{cm}^{2}\end{array}$ \\
\hline A1 & -0.666 & $2.41 \times 10^{-07}$ & 23,670 \\
$\mathrm{~A} 2$ & -0.919 & $7.38 \times 10^{-07}$ & 45,645 \\
$\mathrm{~A} 3$ & -0.864 & $1.35 \times 10^{-06}$ & 62,350 \\
A4 & -0.818 & $2.22 \times 10^{-06}$ & 36,873 \\
A5 & -0.820 & $1.23 \times 10^{-06}$ & 45,350 \\
A6 & -0.770 & $5.25 \times 10^{-07}$ & 92,470 \\
A7 & -0.719 & $2.38 \times 10^{-07}$ & 108,354 \\
A8 & -0.704 & $4.07 \times 10^{-07}$ & 154,166 \\
A9 & -0.669 & $1.46 \times 10^{-06}$ & 57,085 \\
A10 & -0.771 & $1.75 \times 10^{-07}$ & 87,270 \\
A11 & -0.765 & $2.96 \times 10^{-07}$ & 10,276 \\
\hline
\end{tabular}

cerium oxide and graphene compared to pure aluminium. The graphene-only-incorporated aluminium showed the lowest corrosion potential $(-0.919 \mathrm{~V})$. The coupons incorporated with mixtures of nanometre-sized cerium oxide and graphene in 1:1 ratio exhibited a steady increase of $E_{\text {corr }}$ values with increased concentration of nanomaterial whereas in the case of $2: 1$ or $1: 2$ ratio it increased with increased graphene concentration. When the concentration of graphene:nanometre-sized cerium oxide ratio was 1:2, the $E_{\text {corr }}$ decreased significantly. Graphene alone incorporated in aluminium was prone to corrosion probably due to the formation of aluminium carbide (Bartolucci et al. 2011). The lowest corrosion current density $\left(I_{\text {corr }}\right)$ was showed by the coupons A7, A8 and A10, highlighting the corrosion resistance of these materials. The $I_{\text {corr }}$ was the lowest in the case of A7 and it increased in A8 where graphene concentration was more. When graphene:nanometre-sized cerium oxide ratio was 1:2, the $I_{\text {corr }}$ values behaved irregularly. The polarization resistance $\left(R_{\mathrm{p}}\right)$ showed an increase with the concentration of the nanoparticle mixtures. The 1:2 graphene:nanometre-sized cerium oxide-incorporated aluminium showed significantly higher polarization resistance on par with $I_{\text {corr }}$. In the case of 2:1 graphene:nanocerium oxide, the polarisation resistance showed a steady increase with increase of particles in the matrix. Here, the influence of nanometre-sized cerium oxide higher than graphene. The optimum concentration of nanometre-sized cerium oxide and graphene was 0.02:0.04\% since number of particles in the matrix was optimum and lowest $I_{\text {corr }}$ and increased $R_{\mathrm{p}}$. The amount of graphene has no significant influence on corrosion resistance but nanometre-sized cerium oxide addition along with graphene showed notable influence on corrosion resistance.

\section{EIS studies}

EIS of graphene and nanometre-sized cerium oxide-incorporated aluminium were shown in Fig. 6. The highfrequency (HF) and low-frequency (LF) domain of Nyquist plots of pure aluminium generally exhibited an overlapped in the end of the HF and beginning of LF domains, showing there was an association of outermost aluminium oxide layer and the internal layer of the aluminium. Introduction of graphene in the matrix showed different Nyquist plot in which there was a clear separation of HF and LF domains. All coupons with graphene exhibited similar trend. This shows a clear barrier separation between the outermost layer and internal layers of the composite. The graphene flakes might exist in the matrix independently and this has resulted in the increased grain size and surface roughness. The significance of this phenomenon is not known. The impedance data were fitted with simple Randle's equivalent circuit model and the results are shown in Table 3. The exclusive graphene and $0.01 \%$ of each graphene and nanometre-sized cerium oxide-incorporated aluminium showed significantly higher polarization resistance in the high-frequency region than other treatment. This shows the outermost surface layer of the composite was strengthened due to the incorporation of graphene and mixtures of graphene:nanometre-sized cerium oxide $(0.01 \%$ each). These results were correlated with the barrier separation of HF and LF domains. But decreased $R_{\mathrm{p}}$ values in the LF domain indicated that the material was unstable in the internal layers and hence prone to corrosion. Graphene:nanometre-sized cerium oxide-incorporated aluminium in 1:1 ratio showed decreased polarization resistance in both HF and LF domains especially in cases with lower amounts of nanoparticles. When the amount of particles in the matrix was increased, the $R_{\mathrm{p}}$ values were increased in the LF domain up to the particle concentration of $0.05 \%$ each. Further increase of nanometre-sized cerium oxide and graphene concentration resulted in significant reduction in the polarization resistance in both HF and LF frequency domain. This shows increased amounts of graphene and nanocerium oxide was antagonistic to corrosion resistance behaviour. When nanocerium oxide:graphene was incorporated in 1:2 or 2:1 ratios, the composite showed significant improvement in the polarization resistance at LF domain highlighting that these materials were resistant to corrosion in the marine environment. The results showed that nanometre-sized cerium 
Fig. 6 Nyquist plots of graphene-incorporated aluminium (A2) and nanometresized cerium oxide and graphene mixtures in different concentrations incorporated aluminium A3-A11. The measurement was done $\mathrm{Ag}$ / $\mathrm{AgCl}(3 \mathrm{M} \mathrm{KCl})$ as reference, $\mathrm{Pt}$ as counter and sample working electrode in $3.5 \% \mathrm{NaCl}$ at $25 \pm 2{ }^{\circ} \mathrm{C}$. a Circle A2, filled circle $\mathrm{A} 3$, square $\mathrm{A} 4$, filled square $\mathrm{A} 5$, triangle A6. b Circle A7, filled circle A8, square A9, filled square A10, triangle A11
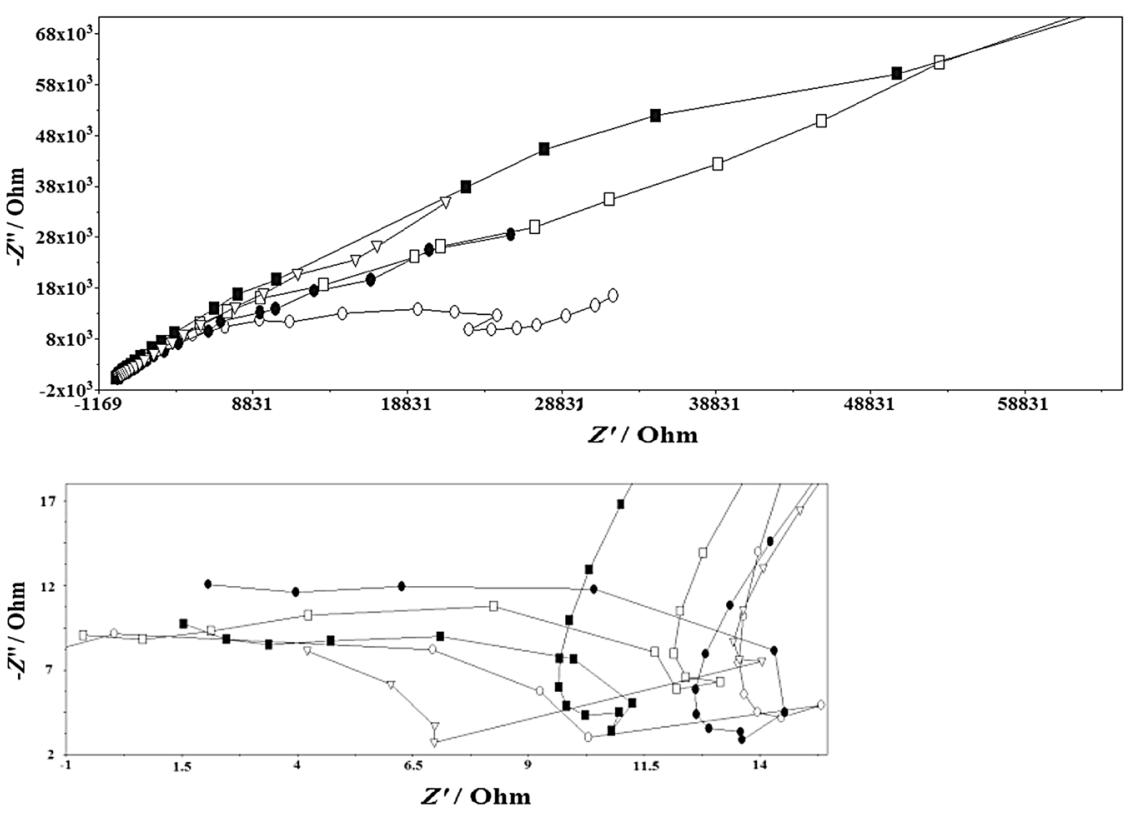

High frequency domain
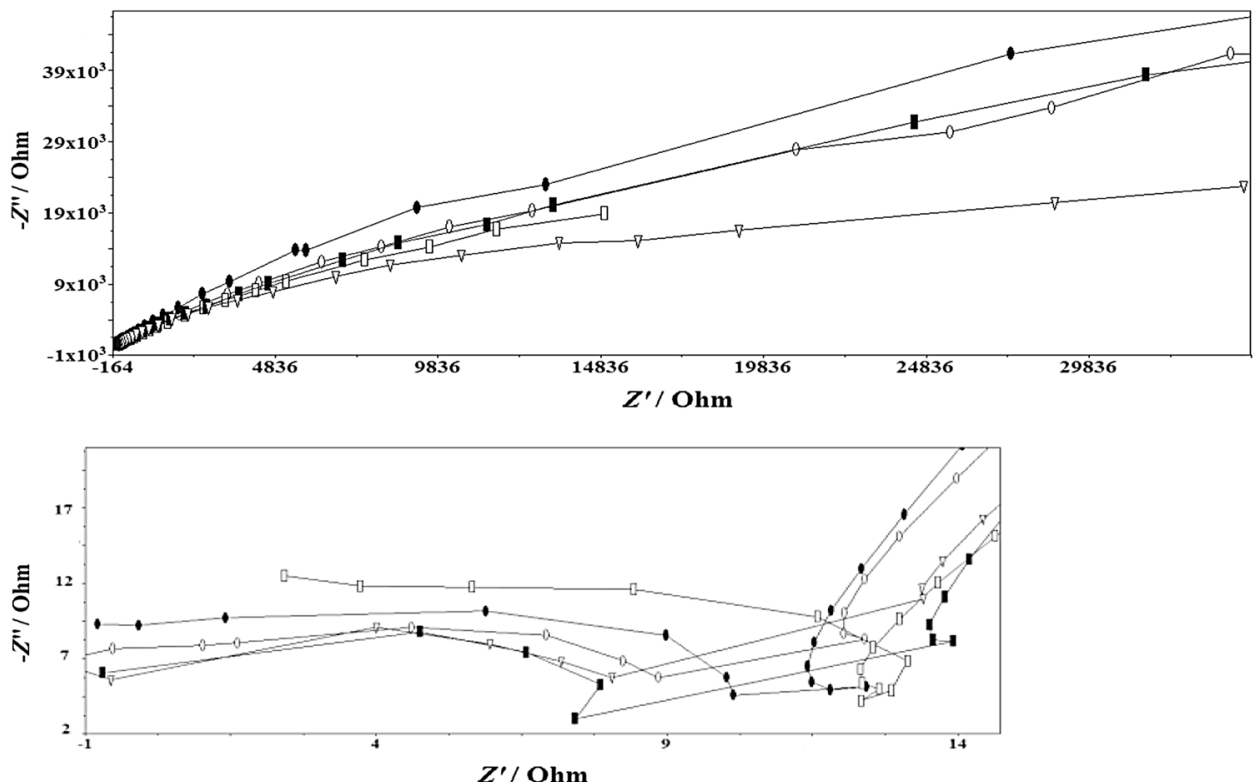

High frequency domain oxide and graphene must not be in equal amounts in aluminium. The concentration of particles in lower amounts will provide excellent corrosion resistance in both internal and surface layers. Constant phase element also exhibited similar trend as described above. The results were further correlated with the findings in the polarization studies and roughness coefficients in the AFM studies. Further the roughness of the material also plays an important role in the corrosion resistance of the material

\section{Weight loss}

Weight loss studies were carried out on coupons of graphene and nanocerium oxide-incorporated aluminium by exposing them in $3.5 \% \mathrm{NaCl}$ at room temperature for 40 days (Fig. 7). The corrosion rate was varied from $9.03 \times 10^{-5}$ to $3.38 \times 10^{-4} \mathrm{mpy}$. The results showed similar trends as in the case of linear sweep voltammetry, AFM roughness and EIS studies. The lowest corrosion resistance was exhibited by the 
Table 3 EIS spectroscopy data of pure aluminium, graphene-incorporated aluminium and mixtures of graphene and nano-sized cerium oxide-incorporated aluminium

\begin{tabular}{lllll}
\hline Treatments & $\begin{array}{l}\text { Polarisation } \\
\text { resistance in } \\
\text { the HF } \\
\text { region } R_{1} \\
\Omega \mathrm{cm}^{2}\end{array}$ & $\begin{array}{l}\text { Polarisation } \\
\text { resistance in } \\
\text { the LF } \\
\text { region } R_{2} \\
\Omega \mathrm{cm}^{2}\end{array}$ & $\begin{array}{l}\text { Constant } \\
\text { phase } \\
\text { element in } \\
\text { the HF } \\
\text { region } C_{1} \\
\mathrm{nF}\end{array}$ & $\begin{array}{l}\text { Constant } \\
\text { phase } \\
\text { element in } \\
\text { the LF } \\
\text { region } \\
C_{2} \mu \mathrm{F}\end{array}$ \\
\hline A1 Pure al & 20.95 & 7810 & 13.33 & 4.39 \\
A2 & 23.09 & 39,085 & 13.74 & 0.95 \\
A3 & 23.03 & 16,893 & 8.73 & 3.10 \\
A4 & 21.19 & 20,435 & 18.96 & 1.25 \\
A5 & 18.41 & 50,517 & 17.48 & 1.24 \\
A6 & 17.11 & 27,576 & 49.54 & 1.37 \\
A7 & 18.48 & 50,122 & 31.37 & 1.15 \\
A8 & 21.05 & 60,244 & 15.81 & 2.56 \\
A9 & 21.89 & 58,542 & 14.66 & 3.28 \\
A10 & 17.95 & 55,302 & 43.70 & 0.88 \\
A11 & 21.20 & 40,027 & 33.28 & 0.89 \\
\hline
\end{tabular}

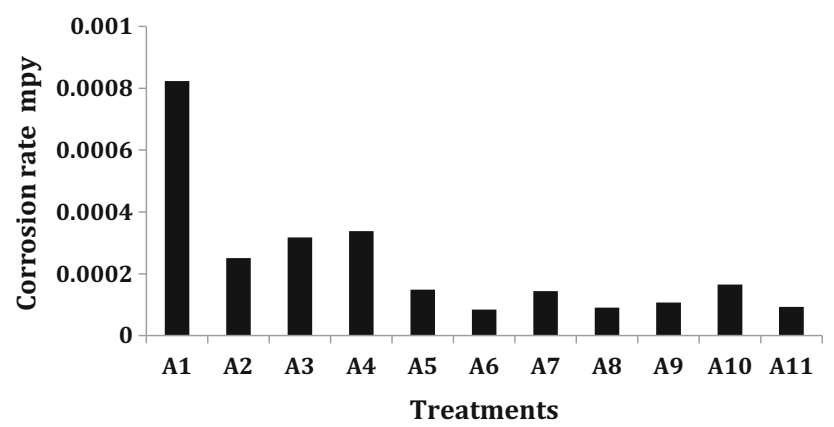

Fig. 7 Corrosion rates of pure aluminium, graphene-incorporated aluminium and graphene and nanometre-sized cerium oxide aluminium after exposing 40 days $3.5 \% \mathrm{NaCl}$

coupons with $0.02 \%$ nanocerium oxide:0.04\% grapheneincorporated aluminium.

\section{OCP evaluation}

OCP of the nanocerium oxide and graphene-incorporated aluminium was evaluated for 40 days by exposing the panels in $3.5 \% \mathrm{NaCl}$ and the results are shown in Fig. 8. The OCP values were comparatively stable in all the cases except in pure aluminium where the standard deviation was comparatively higher. This shows incorporation of nanometre-sized cerium oxide and graphene influenced to stabilize the open circuit potential during long-term exposure in aggressive environments. In the case of $1: 1$ nanometre-sized cerium oxide:graphene similar trend as in

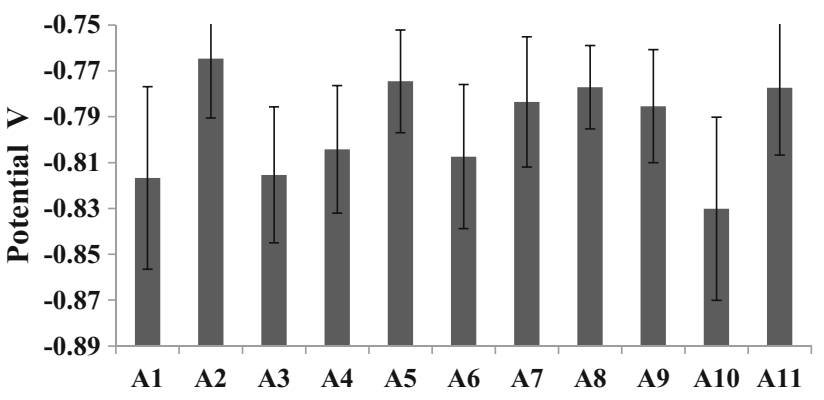

Fig. 8 Average OCP with standard deviation of pure aluminium, graphene-incorporated aluminium and graphene and nanometre-sized cerium oxide aluminium after exposing 40 days $3.5 \% \mathrm{NaCl}$

that of electrochemical evaluation was observed. $0.02 \%$ nanometre-sized cerium oxide:0.04\% graphene showed more stable OCP values and it was evident from its lowest standard deviation. Initially all the panels exhibited potential of $-0.697 \pm 0.011 \mathrm{~V}$ and on third day the OCP was further reduced to $-0.814 \pm 0.023 \mathrm{~V}$. Later the potential of all the coupons were maintained at the potential below the $-0.75 \mathrm{~V}$.

\section{Summary}

Graphene and nanometre-sized cerium oxide-incorporated aluminium was prepared and tested for its corrosion resistance in marine environment. Incorporation of graphene and nano-sized cerium oxide-aluminium improved the surface morphological characteristics as evidenced by roughness indices, AFM and SEM. EIS and linear polarization studies have exhibited that equal ratios of nanomaterial and increased amounts of particles increased corrosion. The ratios $2: 1$ or 1:2 of graphene and nanometresized cerium oxide and trace amounts of particles in the matrix exhibited excellent corrosion resistance in marine environment. Introduction of graphene in aluminium showed a barrier separation between the outermost layer and inner layers, roughness and increased corrosion. The optimum amount of nanometre-sized cerium oxide and graphene for maximum corrosion resistance was 0.02 and $0.04 \%$, respectively. The composite will be a potential candidate for use in marine environment.

Acknowledgments The authors sincerely thank the Director, CIFT for providing facilities and technical staff of the Fishing Technology Division of CIFT.

Open Access This article is distributed under the terms of the Creative Commons Attribution License which permits any use, distribution, and reproduction in any medium, provided the original author(s) and the source are credited. 


\section{References}

Ashraf PM, Edwin L (2013) Corrosion behaviour of nanometre sized cerium oxide and titanium oxide incorporated aluminium in $\mathrm{NaCl}$ solution. J Alloy Compd 548:82-88

Ashraf PM, Shibli SMA (2008) Reinforcing aluminium with cerium oxide: a new and effective technique to prevent corrosion in marine environments. Electrochem Commun 9:443-448

Barraza-Lopez S, Vanevic M, Kindermann M, Chou MY (2010) Effects of metallic contacts on electron transport through graphene. Phys Rev Lett 104:076807

Bartolucci SF, Paras J, Rafiee MA, Rafiee J, Lee S, Kapoor D et al (2011) Graphene-aluminum nano composites. Mater Sci Eng A 528:7933-7937

Berger C, Song Z, Li T, Li X, Ogbazghi AY, Feng R et al (2004) Ultrathin epitaxial graphite: $2 \mathrm{D}$ electron gas properties and a route toward graphene-based nanoelectronics. J Phys Chem B 108:19912-19916

Bertoni G, Calmels L, Altibelli A, Serin V (2005) First-principles calculation of the electronic structure and EELS spectra at the graphene/Ni(111) interface. Phys Rev B 71:075402

Deng CF, Wang DZ, Zhang XX, Li AB (2007) Processing and properties of carbon nanotubes reinforced aluminum composites. Mater Sci Eng, A 444:138-145

Eom D, Prezzi D, Rim KT, Zhou H, Lefenfeld M, Xiao S et al (2009) Structure and electronic properties of graphene nano islands on Co(0001). Nano Lett 9:2844-2848

$\mathrm{Fu}$ YP, Lin $\mathrm{CH}$, Shang CS (2005) Preparation of ultrafine $\mathrm{CeO}_{2}$ powders by microwave-induced combustion and precipitation. J Alloy Compds 391:110-114

Geim AK, Novoselov KS (2007) The rise of graphene. Nat Mater 6:183-191

Giovannetti G, Khomyakov PA, Brocks G, Karpan VM, van den Brink J, Kelly PJ (2008) Doping graphene with metal contacts. Phys Rev Lett 101:026803

Kuzumaki T, Miyazawa K, Ichinose H, Ito K (1998) Processing of carbon nanotube reinforced aluminum composite. J Mater Res $13: 2445-2449$
Marchini S, Günther S, Wintterlin J (2007) Scanning tunneling microscopy of graphene on Ru(0001). Phys Rev B 76:075429

Mattevi C, Kim H, Chhowalla M (2011) A review of chemical vapour deposition of graphene on copper. J Mater Chem 21:3324-3334

Novoselov KS, Geim AK, Morozov SV, Jiang D, Zhang Y, Dubonos $\mathrm{SV}$ et al (2004) Electric field effect in atomically thin carbon films. Science 306:666-669

Novoselov KS, Geim AK, Morozov SV, Jiang D, Katsnelson MI, Grigorieva IV et al (2005) Two-dimensional gas of massless Dirac fermions in graphene. Nature 438:197-200

Pletikosić I, Kralj M, Pervan P, Brako P, Coraux J, N'Diaye AT et al (2009) Dirac cones and minigaps for graphene on $\operatorname{Ir}(111)$. Phys Rev Lett 102:056808

Raposo M, Ferreira Q, Ribeiro P A (2007) A guide for atomic force microscopy analysis of soft condensed matter. In: Méndez-Vilas A, Díaz J(eds) Modern Research and Educational Topics in Microscopy, Formatex, 758A-769

Schedin F, Geim AK, Morozov SV, Hill EW, Blake P, Katsnelson MI et al (2007) Detection of individual gas molecules adsorbed on graphene. Nat Mater 6:652-655

Sutter PW, Flege J-I, Sutter EA (2008) Epitaxial graphene on ruthenium. Nat Mater 7:406-411

Uchoa B, Lin C-Y, Neto AHC (2008) Tailoring graphene with metals on top. Phys Rev B 77:035420

Vanin M, Mortensen JJ, Kelkkanen AK, Garcia-Lastra JM, Thygesen KS, Jacobsen KW (2010) Graphene on metals: a van der Waals density functional study. Phys Rev B 81:081408(R)

Varykhalov A, Sánchez-Barriga J, Shikin AM, Biswas C, Vescovo E, Rybkin A et al (2008) Electronic and magnetic properties of quasi freestanding graphene on Ni. Phys Rev Lett 101:157601

Wehling TO, Novoselov KS, Morozov SV, Vdovin EE, Katsnelson MI, Geim AK et al (2008) Molecular doping of graphene. Nano Lett 8:173-177

Wintterlin J, Bocquet ML (2009) Graphene on metal surfaces. Surface Sci 603:1841-1852

Zhang YB, Tan YW, Stormer HL, Kim P (2005) Experimental observation of the quantum Hall effect and Berry's phase in graphene. Nature 438:201-204 